\title{
Sosyal Medya Bağımlılığı: Üniversite Öğrencileri Üzerine Çalışma ${ }^{1}$
}

\author{
DOI: $10.26466 /$ opus.470118
}

\begin{abstract}
$\underline{\text { Fatih Çağatay Baz }}^{*}$
*Dr. Öğr. Üyesi, Osmaniye Korkut Ata Üniversitesi, İktisadi ve İdari Bilimler Fakültesi, Fakıuşağı / Osmaniye / Türkiye

E-Posta: fatihcagataybaz@osmaniye.edu.tr

ORCID: 0000-0002-6398-9851
\end{abstract}

\section{$\ddot{O} z$}

Günümüzde, özellikle gençler arasında, internet kullanımı çok yaygındır. Internet kullanımı en çok sosyal medya alanında tercih edilmektedir. Sosyal medya haber, iletişim, eğitim, bilgi paylaşımı, arkadaş takibi gibi farklı alanlarda ilgi çekmektedir. Sosyal medya insanlara düşüncelerini ve edinimlerini paylaşabilecekleri geniş bir alan sunmaktadır. Bu çalışma ile sosyal medya bağımlılıkları üzerine Osmaniye Korkut Ata Üniversitesi öğrencileri örnekleminde ölçek uygulanarak, sosyal medya bağımlılıları analiz edilmektedir. Verilerin analizinde betimsel istatistik yöntemleri, bağımsız örneklemler için $t$ testi ve tek yönlü varyans analizi kullanılmıştır. Araştırmada farklı bölümlerden 186 öğrenci ile gerçekleştirilmiştir. Bu çalı̧̧mada Şahin (2018) tarafından geliştirilen ortaokul, lise ve üniversite öğrencilerinin sosyal medya bağımlılı düzeylerini belirlemek amacıyla, geçerlik çalışmaları çerçevesinde açımlayıcı ve doğrulayıcı analizleri yapılmış ve SMBÖ-YF'nun beşli Likert tipi, 4 alt boyut (sanal tolerans, sanal iletişim, sanal problem ve sanal bilgilenme) ve 29 maddeden oluşan bir yapıya sahip olan ölçek kullanılmıştır. Elde edilen veriler ışığında öğrencilerin sosyal medya kullanıcısı oldukları ancak sosyal medya kullanımından kaynaklı sorunları bağımlılık düzeyinde yaşamadıklar ile belirlenmiştir. Sosyal medya bağımlılı̆̆ konusunda öğrenci görüşlerinin cinsiyet, yaş, aylık harcama miktarı ve öğrenim gördükleri bölüm gibi değişkenler açısından önemli farklılıklar görülmemiştir.

Anahtar Kelimeler: Sosyal medya, Sosyal medya bağımlılı̆̆ı, Üniversite öğrencileri

\footnotetext{
${ }^{1}$ 6-8 Nisan 2018 Tarihinde Gaziantep'te Yapılan Al-Farabi 3.Uluslarası Sosyal Bilimler Kongresinde Bildiri Özeti Olarak Sunulmuştur.
}

OPUS (c) Uluslararası Toplum Araştırmaları Dergisi-International Journal of Society Researches ISSN:2528-9527 E-ISSN : 2528-9535

http://opusjournal.net 


\title{
Social Media Addiction: Study on University Students
}

\begin{abstract}
Today, especially among young people, the use of internet is very common. Internet use is mostly preferred in social media. Social media is attracting attention in different fields such as news, communication, education, information sharing and friend tracking. Social media offers people a wide range of space to share their thoughts and acquisitions. In this study, social media dependencies are analyzed by applying a questionnaire in Osmaniye Korkut Ata University students' sample on social media dependencies. In the analysis of the data, descriptive statistical methods, $t$ test for independent samples and one-way analysis of variance were used. 186 students from different departments were employed in the study. In this study, to determine social media addiction levels of secondary school, high school and university students developed by Şahin (2018), exploratory and validator analyzes were conducted within the framework of validity studies, and SMBÖ-YF's fivepoint Likert type, 4 sub-dimensions (virtual tolerance, virtual communication, virtual problem and virtual knowledge) and a scale consisting of 29 items. In the light of the data obtained, it was determined that students were social media users, but they did not experience social media usage problems at the level of dependency. There were no significant differences in terms of variables such as gender, age, monthly expenditure and the department in which they studied.
\end{abstract}

Keywords: Using internet, Internet addiction, University students

OPUS (c) Uluslararası Toplum Araştırmaları Dergisi-International Journal of Society Researches ISSN:2528-9527 E-ISSN : 2528-9535

http://opusjournal.net 


\section{Giriş}

İnternet kullanımı günden güne hızlı şekilde artmaktadır. Özellikle gençler arasında bu artış gerçekleşmektedir. İnternet kullanımı en çok sosyal medya alanında tercih edilmektedir. Sosyal medya haber, iletişim, eğitim, bilgi paylaşımı, arkadaş takibi gibi farklı alanlarda ilgi çekmektedir. Sosyal medya insanlara düşüncelerini ve edinimlerini paylaşabilecekleri geniş bir alan sunmaktadır. Aynı zamanda sosyal medya, insanların zamanını eğlence anlamında geçirmelerinden, alışveriş yapmak istemelerine kadar çok yönlü etkilemektedir.

İnternet kullanımı ile veriler küresel boyutta kitlelere yayılabilmektedir. İnternet aynı zamanda kamu alanında ve özel alanlarda sosyal etkileşim için bir imkân sağlamaktadır. Günümüzün sanal ortam kullanıcıları tarafından adeta bir bağımlılık haline gelen sosyal medya kullanımı, her kültürden ve her kesimden geniş kitlelerin, sosyal taleplerine cevap vermesinin yanı sıra, bu ortama eleştiride bulunanların hedefinde yer almaktadır. Yeni iletişim ortamlarının gelişmesi, her kesimden bilgi iletişim teknolojilerine olan ilginin artması, sosyal medyanın gücünü arttırmakta, sosyalleşme kavramına da farklı bir boyut kazandırmaktadır. Her geçen gün yeni güncellemeler ile karşımıza çıkan internet adeta sosyal medya ile altın çağını yaşamaktadır. Sosyal medya ile internet insanların yaşamlarına dokunmaktadır. (Vural \& Bat, 2010; Solmaz, Tekin, Herzem \& Demir, 2013; Sağbaş, Ballı \& Şen, 2016).

İnsanlar sosyal medya araçlarını tanıdıkları ile görüşmek, arkadaşlarının fotoğraflarına bakmak, mesajlaşmak, iletilerini takip etmek, bilgi amaçlı kullanmak, boş zamanlarında eğlenmek için kullanmaktadır. Demir (2016), internetin sağladığ pek çok olanak sebebiyle yaşamı kolaylaştırdığını ifade etmektedir. Sağladığı olanaklardan birisi kolay ve hızlı iletişim imkânı tanımasıdır. Ayrıca internet ortamında iletişim sağlayan en temel aracın sosyal medya olduğunu belirtmektedir.

Günümüz bilgi çağında iletişim araçları da değişiklik göstermiştir. Çok fonksiyonlu olan internet önemli bir iletişim aracı haline gelmiştir (Çakmak, 2014). Yaşamımıza hızla giren internet şüphesiz beraberinde birtakım sorunları da getirmiştir. Yaptıkları çalışmada her çeşit yazı, görsel, video, oyun, grafik ve bunlara benzeyen iletişim türlerinin multimedya olarak sunulabildiğini belirten Işık ve Topbaş (2015); bu 
etkileşimli ortamların kullanıcılar için bağımlılık nesneleri barındırdığını belirtmişlerdir. Yine benzer çalışmalar kullanıcıların sosyal medya araçları kullanımı sebebiyle bağımlılık durumlarını ortaya koymaktadır (Kuss \& Griffiths, 2011; Kara, 2012; Küçükali, 2016; Nakaya, 2015; Öngen, 2017).

Sosyal medyanın kullanıcılar açısından bağımlılık haline gelmesi birtakım sorunları da beraberinde getirmektedir. Yüz yüze görüşmeler yerini sanal ortamlara bırakmıştır. Sosyal medya bağımlılığının boş zaman harcamaya ve bunun akademik başarısızlığa neden olduğu yine yapılan çalışmalarda görülmektedir. (Cabral, 2011; Menayes, 2015; Kırık \& diğ., 2015; Hawi \& Samaha, 2017).

$\mathrm{Bu}$ araştırmanın amacı, üniversite öğrencilerinin sosyal medya bağımlılıklarına yönelik görüşlerini belirlemektir. Ayrıca öğrencilerin yaş, cinsiyet, aylık olarak para harcama miktarları, okudukları bölümler gibi değişkenlerin öğrencilerin konuya ilişkin görüşlerinde farklılık yaratıp yaratmadıklarının ortaya konulması amaçlanmıştır.

Çalışmanın amacı doğrultusunda, aşağıda belirtilen probleme ilişkin cevap bulunmaya çalışılmıştır.

“Osmaniye Korkut Ata Üniversitesinde öğrenim gören öğrencilerin, sosyal medya bağımlılığı üzerine görüşleri nelerdir?"

Ayrıca çalışmanın alt problemleri olarak şunları sıralamak mümkündür:

1. Üniversitede öğrenim görmekte olan öğrencilerin, sosyal medya bağımlılığı üzerine görüşleri cinsiyet değişkenine göre farklılaşmakta mıdır?

2. Üniversitede öğrenim görmekte olan öğrencilerin, sosyal medya bağımlılığı üzerine görüşleri yaş değişkenine göre farklılaşmakta midır?

3. Üniversitede öğrenim görmekte olan öğrencilerin, sosyal medya bağımlılığı üzerine görüşleri okudukları bölüm değişkenine göre farklılaşmakta mıdır?

4. Üniversitede öğrenim görmekte olan öğrencilerin, sosyal medya bağımlılığı üzerine görüşleri aylık ortalama harcama miktarı değişkenine göre farklılaşmakta mıdır? 
Alanyazın incelendiğinde Osmaniye ilinde üniversite öğrencilerinin sosyal medya bağımlılığına yönelik görüşlerinin incelendiği herhangi bir araştırmaya rastlanmamıştır. Bu anlamda yapılan çalışmanın önem arz ettiği düşünülmektedir.

\section{Yöntem}

\section{Araştırma Modeli}

Yapılan bu çalışmada araştırma genel tarama modeline göre tasarlanmıştır. Genel tarama modelini Karasar (2009); çok sayıda elemandan oluşan bir evrende, evren hakkında genel bir yargıya varmak amacı ile, evrenin tümü ya da ondan alınacak bir grup, örnek ya da örneklem üzerinde yapılan tarama düzenlemeleridir olarak yapmaktadır.

\section{Evren ve Örneklem}

Çalışma evrenini 2017-2018 eğitim-öğretim yılı bahar döneminde Osmaniye Korkut Ata Üniversitesi'nde öğrenim gören lisans öğrencileri oluşturmaktadır. Çalışmanın örneklemini ise İktisadi ve İdari Bilimler Fakültesi'nde bulunan 3 bölüm (İktisat, Uluslararası Ticaret ve Lojistik, Yönetim Bilişim Sistemleri) toplam 186 adet öğrenci oluşturmaktadır. Örneklem belirlenirken seçkisiz olmayan örnekleme yöntemlerinden, amaçsal örnekleme yöntemi tercih edilmiştir. Büyüköztürk (2012) amaçsal örnekleme yöntemini; derinlemesine araştırma yapabilmek amacıyla çalışmanın amacı bağlamında bilgi açısından zengin durumların seçilmesidir şeklinde ifade etmektedir.

Tablo 1'de araştırma yapılan bölümler ve öğrenci sayıları verilmiştir.

Tablo 1. Araştırma Yapılan Bölümler ve Öğrenci Sayısı Dağılımları

\begin{tabular}{ccc}
\hline No & Araştırma Yapılan Bölüm & Öğrenci Sayısı \\
\hline 1 & Yönetim Bilişim Sistemleri & 70 \\
2 & Uluslararası Ticaret ve Lojistik & 63 \\
3 & İktisat & 53 \\
Toplam & & 186 \\
\hline
\end{tabular}


Araştırmaya toplamda 186 öğrenci katılmıştır. Bu öğrencilerin sayılarının dağılımları Tablo 1'de verildiği üzere 70'i Yönetim Bilişim Sistemleri, 63'ü Uluslararası Ticaret ve Lojistik, 53'ü ise İktisat bölümünden oluşmaktadır.

\section{Veri Toplama Araci}

Araştırmada veri toplamak amacıyla ölçek uygulanmıştır. Ölçek iki bölümden oluşmaktadır. Birinci bölümde kişisel değişkenler ile ilgili maddeler (cinsiyet, yaş, bölüm, aylık harcama miktarı) yer almaktadır. Ölçeğin ikinci bölümünde kullanılan ölçme aracı Şahin (2018) tarafından ortaokul, lise ve üniversite öğrencilerinin sosyal medya bağımlılık düzeylerini belirlemek amacıyla geliştirilmiştir. Gerçekleştirilen geçerlik çalışmaları çerçevesinde açımlayıcı ve doğrulayıcı analizleri yapılmış ve SMBÖ-YF' nun beşli Likert tipi, 4 alt boyut (sanal tolerans, sanal iletişim, sanal problem ve sanal bilgilenme) ve 29 maddeden oluşan bir yapıya sahip olduğu belirlenmiştir. Sanal tolerans alt boyutu 1-5'inci, sanal iletişim 6-14'üncü, sanal problem 15-23'üncü ve sanal bilgilenme ise 2429'uncu maddelerden oluşmaktadır. Ölçeğin KMO katsayıs1 .96; Barlet anlamlılık değeri $\chi 2=12680.88(\mathrm{p}=.00)$ düzeyinde anlamlı bulunmuştur. Tüm ölçek için iç tutarlılık katsayısı (Cronbach Alpha katsayısı) 93 olarak bulunmuş; alt faktörler için ise, iç tutarlılık katsayıları ise .81 ile .86 arasında değerler aldığı görülmektedir. Ayrıca ölçeğin test-tekrar test katsayısı .94 olarak bulunmuştur. Analizler SMBÖ-ÖF' nin, öğrencilerin sosyal medya bağımlılığını belirlemeye yönelik geçerli ve güvenilir bir ölçek olduğunu ortaya koymuştur. Ölçekten alınabilecek en yüksek puan 145 , en düşük puan ise $29^{\prime}$ dur. Puanın yüksek olması bireyin kendisini "sosyal medya bağımlısı" olarak algıladığı biçiminde değerlendirilmektedir.

\section{Verilerin Analizi}

Araştırmada kullanılan ölçek sonuçlarından elde edilen veriler SPSS 25.0 programı aracilığ1 ile analiz edilmiştir. Verilerin analizinde betimsel istatistik, bağımsız örneklemler için $t$ testi ve tek yönlü varyans analizi 
kullanılmıştır. Çalışmada "tanımlayıcı istatistik" yöntemi ile araştırmaya katılan öğrencilerin sosyal medya bağımlılığına ilişkin görüşlerinin "frekans yüzde dağılımları" ile birlikte "aritmetik ortalamaları" hesaplanmıştır.

\section{Bulgular ve Tartışma}

Araştırmada elde edilen verilerin istatistiksel olarak yapılan çözümlerinden elde edilen bulgulara bu kısımda yer verilmiştir.

Üniversitede öğrenim görmekte olan öğrencilerin sosyal medya bağımlılıkları ile ilgili görüşlerinin dağılımı Tablo 2'de verilmiştir.

Tablo 2. Öğrencilerin Sosyal Medya Bağımlılı̆̆ına Yönelik Görüşlerinin Frekans Yüzde Dağılımlan ve Aritmetik Ortalamaları

\begin{tabular}{|c|c|c|c|c|c|c|c|c|c|c|c|}
\hline \multirow[t]{2}{*}{ Önermeler } & \multicolumn{2}{|c|}{$\begin{array}{l}\text { Bana Hiç } \\
\text { Uygun } \\
\text { Değil }\end{array}$} & \multicolumn{2}{|c|}{$\begin{array}{l}\text { Bana } \\
\text { Uygun } \\
\text { Değil }\end{array}$} & \multicolumn{2}{|c|}{ Kararsızım } & \multicolumn{2}{|c|}{$\begin{array}{l}\text { Bana } \\
\text { Uygun }\end{array}$} & \multicolumn{2}{|c|}{$\begin{array}{l}\text { Bana Çok } \\
\text { Uygun }\end{array}$} & \multirow[t]{2}{*}{$\bar{X}$} \\
\hline & $\mathrm{f}$ & $\%$ & $\mathrm{f}$ & $\%$ & $\mathrm{f}$ & $\%$ & $\mathrm{f}$ & $\%$ & $\mathrm{f}$ & $\%$ & \\
\hline $\begin{array}{l}\text { 1.Sosyal medyaya girmek } \\
\text { için sabırsızlanırım. }\end{array}$ & 46 & 24,7 & 52 & 28 & 35 & 18,8 & 36 & 19,4 & 17 & 9,1 & 2,6 \\
\hline $\begin{array}{l}\text { 2.Sosyal medyaya gire- } \\
\text { bilmek için her yerde } \\
\text { internet bağlantısı ararım. }\end{array}$ & 53 & 28,5 & 39 & 21 & 43 & 23,1 & 29 & 15,6 & 22 & 11,8 & 2,61 \\
\hline $\begin{array}{l}\text { 3.Sabah uyandığımda ilk } \\
\text { işim sosyal medyaya } \\
\text { girmek olur. }\end{array}$ & 38 & 20,4 & 39 & 21 & 33 & 17,7 & 45 & 24,2 & 31 & 16,7 & 2,95 \\
\hline $\begin{array}{l}\text { 4.Sosyal medyayı gerçek } \\
\text { dünyadan bir kaçış olarak } \\
\text { görüyorum. }\end{array}$ & 52 & 28 & 39 & 21 & 43 & 23,1 & 34 & 18,3 & 18 & 9,7 & 2,6 \\
\hline $\begin{array}{l}\text { 5.Sosyal medyasız bir } \\
\text { yaşam bana anlamsız gelir. }\end{array}$ & 62 & 33,3 & 50 & 26,9 & 39 & 21 & 26 & 14 & 9 & 4,8 & 2,3 \\
\hline $\begin{array}{l}\text { 6.Çevremde birileri varken } \\
\text { bile, sosyal medyada } \\
\text { olmayı tercih ederim. }\end{array}$ & 65 & 34,9 & 57 & 30,6 & 43 & 23,1 & 14 & 7,5 & 7 & 3,8 & 2,14 \\
\hline $\begin{array}{l}\text { 7.Sosyal medyadaki arka- } \\
\text { daşlıkları gerçek yaşamda- } \\
\text { ki arkadaşlıklara tercih } \\
\text { ederim. }\end{array}$ & 117 & 62,9 & 38 & 20,4 & 16 & 8,6 & 12 & 6,5 & 3 & 1,6 & 1,63 \\
\hline $\begin{array}{l}\text { 8.Sosyal medyada bağlantı } \\
\text { kurduğum insanlara } \\
\text { kendimi daha iyi an- } \\
\text { latıyorum. }\end{array}$ & 76 & 40,9 & 45 & 24,2 & 35 & 18,8 & 19 & 10,2 & 11 & 5,9 & 2,16 \\
\hline $\begin{array}{l}\text { 9.Sosyal medyada } \\
\text { görünmek istediğim gibi } \\
\text { oluyorum. }\end{array}$ & 63 & 33,9 & 35 & 18,8 & 34 & 18,3 & 35 & 18,8 & 19 & 10,2 & 2,52 \\
\hline
\end{tabular}


Fatih Çağatay Baz

10.İnsanlarla iletişimi

68

$36,6 \quad 43$

23,

39

21

27

14,5

4,8

2,27

aracılığı ile kurmayı tercih

ederim.

11. Ailem karşı çıksa dahi

sosyal medyayı kullanmak-

tan bir türlü vazgeçemi-

yorum.

12. Yalnız kaldığımda

sosyal medyada zaman

geçirmek isterim.

13. Sosyal medyada sanal

iletişim kurmayı dışarı

çımaya tercih ederim.

14. Sosyal medya etkin-

likleri, günlük yaşamımı

ele geçiriyor.

15. Sosyal medyada çok

zaman geçirdiğimden

ödevlerimi aksatırım.

16. Sosyal medyada

geçirdiğim zamanı azalt-

mak zorunda kalırsam

üzülürüm.

17. Sosyal medyada olma-

dığım zaman mutsuz

olurum.

18. Sosyal medyada olmak

beni heyecanlandırır.

19. Sosyal medyayı sık sık

kullanmamdan dolayı

ailem ile sorunlar

yaşıyorum.

20. Sosyal medyanın

gizemli dünyası, beni her

zaman tutsak eder.

21. Sosyal medyada iken aç

80

43

49

$26,3 \quad 22$

$11,8 \quad 26$

$\begin{array}{lll}14 & 9 & 4,8\end{array}$

2,11

$9,7 \quad 28$

$15,1 \quad 32$

$17,2 \quad 65$

$34,9 \quad 43$

$23,1 \quad 3,46$

89

$47,8 \quad 44$

$23,7 \quad 24$

$12,9 \quad 18$

$9,7 \quad 11$

$5,9 \quad 2,02$

77

$41,4 \quad 4$

$22,6 \quad 40$

$21,5 \quad 15$

$8,1 \quad 12 \quad 6,5$

2,15

78

$41,9 \quad 48$

$25,8 \quad 36$

$19,4 \quad 17$

88

$47,3 \quad 53$

$28,5 \quad 28$

$15,1 \quad 13$

87

$46,8 \quad 46$

$24,7 \quad 34$

18,

$65 \quad 34,9 \quad 56$

$30,1 \quad 48$

$25,8 \quad 1$

110

$59,1 \quad 39$

21

$12,4 \quad 9$

$4,8 \quad 5$

$2,7 \quad 1,7$

ve susuz kaldığımın

farkına bile varmam.

22. Sosyal medya yüzün-

den verimliliğimin

azaldığını fark ediyorum.

23. Sosyal medya

kullanımım yüzünden

bedensel sorunlar

yaşıyorum.

24. Sosyal medyayı anlık

gelişmelerden haberdar

65

88

$47,3 \quad 5$

26,9

118

$63,4 \quad 40$

$21,5 \quad 17$

$9,1 \quad 8$

$4,3 \quad 3$

1,6

1,59

72

$38,7 \quad 39$

21

$19,4 \quad 25$

$13,4 \quad 14 \quad 7,5$

2,3

$51,6 \quad 4$

22,

14

13

7

$4,8 \quad 1,9$

olmak için yolda yürürken

bile kullanırım.

25. Sosyal medyayı

kullanmayı olup biten-

lerden haberdar olmak için

31

$16,7 \quad 20$

$10,8 \quad 28$

$15,1 \quad 6$

$35,5 \quad 4$

22

3,35 
seviyorum.

26. Sosyal medya gruplarının paylaşımlarından haberdar olmak için sosyal medyada gezinirim.

27. Özel bazı duyuruları (doğum günü vb.) görebilmek için sosyal medyada daha çok zaman geçiriyorum.

28. Derslerimle ilgili çalışmalardan (ödev, etkinlikler vb.) haberdar olmak beni her zaman sosyal medyada kalmaya zorluyor.

29. Yakın çevremin paylaşımlarından hemen haberdar olmak için sosyal medyada sürekli aktif olurum.

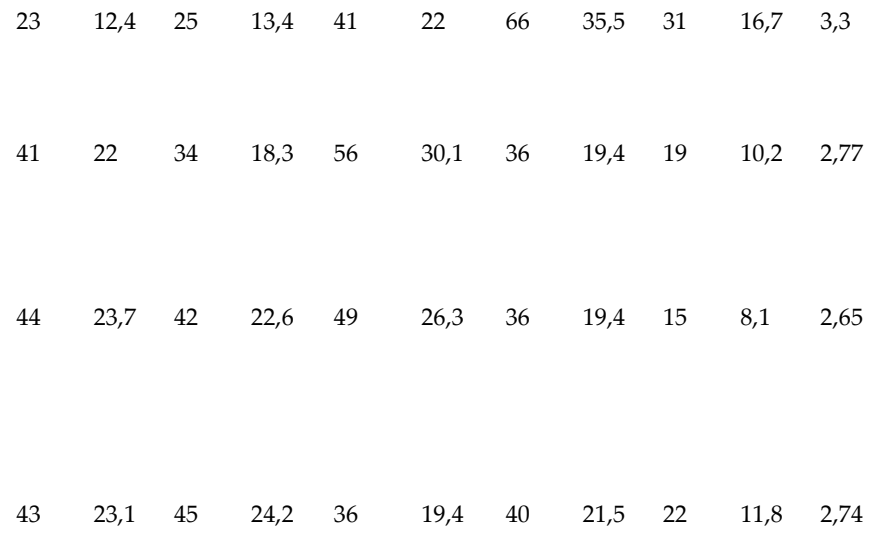

Tablo 2 incelendiğinde öğrencilerin en çok (\%58) "Yalnız kaldığımda sosyal medyada zaman geçirmek isterim" önermesine katıldıkları görülmektedir. "Sosyal medyayı kullanmayı olup bitenlerden haberdar olmak için seviyorum" önermesi öğrencilerin en çok katıldıkları (\%57) bir diğer madde olmuştur. Yine araştırmaya katılan öğrencilerin çoğunlukta bir bölümü (\%52) "Sosyal medya gruplarının paylaşımlarından haberdar olmak için sosyal medyada gezinirim" önermesine katıldıklarını belirtmektedirler. Ayrıca \%41 oranında öğrenci "Sabah uyandığımda ilk işim sosyal medyaya girmek olur" görüşünü ifade etmektedir.

Sosyal medya bağımlılı̆̆ı anlamında üniversite öğrencilerinin verileri değerlendirildiğinde, "Sosyal medyada iken aç ve susuz kaldığımın farkına bile varmam" önerisine en düşük oranda (\%6) katıldıkları görülmektedir. Öğrencilerin sosyal medya bağımlılı̆̆ı konusunda önemli bir diğer sonuç ise "Sosyal medyayı sık sık kullanmamdan dolayı ailem ile sorunlar yaşıyorum" önerisidir. Bu öneriye öğrenciler \%7 gibi düşük bir oran ile katılmaktadır. "Sosyal medyadaki arkadaşlıkları gerçek yaşamdaki arkadaşlıklara tercih ederim" \%8 oranında öğrencilerin katıldıkları başka bir düşük oranlı öneridir. 


\section{Alt Problemlere İlişkin Bulgular}

1. Üniversitede öğrenim görmekte olan öğrencilerin, sosyal medya bağımlılı̆̆ı üzerine görüşlerinin cinsiyet değişkenine göre farklılığına ilişkin bulgular:

Üniversite öğrencilerinin sosyal medya bağımlılığına yönelik görüşleri ile cinsiyetleri arasında anlamlı bir farklılığın olup olmadığ 1 ilişkisiz ttesti ile belirlenmiştir. Üniversite öğrencilerinin sosyal medya bağımlılığı görüşlerinin, cinsiyet değişkenine göre farklılaşıp farklılaşmadı̆̆ sonucu Tablo $3^{\prime}$ te verilmiştir.

Tablo 3. Cinsiyete Göre Üniversite Öğrencilerinin Sosyal Medya Bağımlılı̆̆ına Yönelik Görüşlerinin t testi Sonuçlarn

\begin{tabular}{llllll}
\hline Cinsiyet & $\mathbf{N}$ & $\overline{\mathbf{X}}$ & $\mathbf{s d}$ & $\mathbf{t}$ & $\mathbf{p}$ \\
\hline Kadın & 79 & 2,40 & 184 & 0,904 &, 367 \\
Erkek & 107 & 2,31 & & & \\
\hline
\end{tabular}

Tablo 3'e göre çalışma grubundaki kadınların sosyal medya bağımlılığına yönelik görüşlerinin toplam puanlarının aritmetik ortalamasının $\bar{X}=2,40$ olduğu, erkek öğrencilerin aritmetik ortalamasının ise $\bar{X}=2,31$ olduğu görülmektedir. Öğrencilerin sosyal medya bağımlılı̆̆ına yönelik görüşleri toplamı ile cinsiyet arasındaki ilişki incelenmiş ve istatistiksel açıdan anlamlı bir fark bulunamamıştır [sig. $\mathrm{p}>, 05]$. Bu verilerden yola çıkarak öğrencilerin sosyal medya bağımlılığına yönelik görüşlerinde cinsiyet faktörünün önemli olmadığı söylenebilir.

2. Üniversitede öğrenim görmekte olan öğrencilerin, sosyal medya bağımlılı̆̆ı üzerine görüsşlerinin yaş değişkenine göre farklılı̆̆ına ilişkin bulgular:

Üniversite öğrencilerinin sosyal medya bağımlılığına yönelik görüşleri ile yaş değişkeni arasında anlamlı bir farklılığın olup olmadığı araştırılmıştır. 
Tablo 4. Yaş Dağılımlarna Göre Üniversite Öğrencilerinin Sosyal Medya Bă̆ımlılı̆̆ına Yönelik Görüşlerinin Tek Yönlü Varyans Analizi (ANOVA) Sonuçları

\begin{tabular}{llllll}
\hline Değişken & Yaş Aralığı & $\mathbf{N}$ & $\overline{\mathbf{X}}$ & $\mathbf{S}$ & \\
& $18-21$ Yaş & 58 & 2,425 &, 730 & \\
& $21-24$ Yaş & 111 & 2,305 &, 704 & \\
& 24 -üzeri & 17 & 2,421 &, 830 & \\
\hline \multirow{2}{*}{ Yaş Aralığı } & Varyansın & KT & sd & F & p \\
& Kaynağı & & & & \\
\hline & Gruplar arası &, 637 & 2 &, 607 & \\
& Gruplar içi & 96,053 & 183 & & \\
& Toplam & 96,690 & 185 & & \\
\hline
\end{tabular}

Tablo 4 incelendiğinde üniversite öğrencilerinin sosyal medya bağımlılığına ilişkin görüşleri ölçeği toplam puanları ortalaması yaş aralığına göre anlamlı bir farklılık göstermemiştir $[\mathrm{F}=, 607 ; \mathrm{p}>, 05]$. Bu araştırma sonucuna göre 18-21 yaş aralığında olan öğrencilerin $(\overline{\mathrm{X}}=$ 2,425) 24 yaş üzeri öğrencileri $(\bar{X}=2,421)$ ile sosyal medya bağımlılığ konusunda neredeyse eşit oldukları ifade edilebilir. 21-24 yaş aralığındaki öğrencilerin ise $(\bar{X}=2,305)$ sosyal medya bağımlılı̆̆ konusunda diğer ikiliye yakın oldukları söylenebilir.

3. Üniversitede öğrenim görmekte olan öğrencilerin, sosyal medya bağımlılı̆̆ı üzerine görüşlerinin okudukları bölüm değişkenine göre farklılı̆̆ına ilişkin bulgular:

Üniversite öğrencilerinin sosyal medya bağımlılığına yönelik görüşleri ile okudukları bölümleri arasında anlamlı bir farklılığın olup olmadığı araştırılmıştır.

Üniversite öğrencilerinin sosyal medya bağımlılığına yönelik görüşlerinin bölüm değişkenine göre farklılık gösterip göstermediğini belirlemek için "Tek Yönlü Varyans Analizi (ANOVA)" yapılmıştır. Bu analizin sonuçları Tablo 5 ' te verilmiştir. 
Tablo 5. Bölümlere Göre Üniversite Öğrencilerinin Sosyal Medya Bağımlılı̆̆ına Yönelik Görüşlerinin Tek Yönlü Varyans Analizi (ANOVA) Sonuçları

\begin{tabular}{llllll}
\hline Değişken & Bölüm & $\mathbf{N}$ & $\overline{\mathbf{X}}$ & $\mathbf{S}$ & \\
\hline & İktisat & 53 & 2,30 &, 731 & \\
& UTL & 63 & 2,25 &, 763 & \\
& YBS & 70 & 2,48 &, 667 & \\
\hline Sinıf & Varyansın & KT & sd & F & p \\
Düzeyi & Kaynağ1 & & & & \\
\hline & Gruplar arası & 1,912 & 2 & 1,845 &, 161 \\
& Gruplar içi & 94,778 & 183 & & \\
& Toplam & 96,690 & 185 & & \\
\hline
\end{tabular}

Tablo 5 incelendiğinde üniversite öğrencilerinin sosyal medya bağımlılığına ilişkin görüşleri ölçeği toplam puanları ortalaması bölümlere göre anlamlı bir farklılık göstermemiştir [F=1,845; $\mathrm{p}>, 05]$. Bu anlamda sig. değeri $0,05^{\prime}$ ten büyük çıktığ için post-hoc testi yapılmamıştır. $\mathrm{Bu}$ araştırma sonucuna göre Yönetim ve Bilişim Sistemlerinde (YBS) okuyan öğrencilerin $(\bar{X}=2,48)$ İktisat $(\bar{X}=2,30)$ ve Uluslararası Ticaret ve Lojistik (UTL) bölümünde öğrenim gören öğrencilerden $(\bar{X}=2,25)$ sosyal medya konusunda daha bağımlı oldukları söylenebilir.

4. Üniversitede öğrenim görmekte olan öğrencilerin, sosyal medya bağımlılı̆̆ değişkenine göre farkhlı̆̆ına ilişkin bulgular:

Üniversite öğrencilerinin sosyal medya bağımlılığına yönelik görüşleri ile aylık ortalama harcama miktarları arasında anlamlı bir farklılığın olup olmadığı araştırılmıştır.

Tablo 6 incelendiğinde üniversite öğrencilerinin sosyal medya bağımlılığına ilişkin görüşleri ölçeği toplam puanları ortalaması aylık harcama miktarlarına göre anlamlı bir farklılık göstermemiştir [F= ,292; $\mathrm{p}>, 05]$. Bu araştırma sonucuna göre 0-500 TL aylık harcama miktarına sahip öğrencilerin $(\bar{X}=2,30)$ aylik 500-1000 TL harcama miktarına sahip öğrencilerin $(\bar{X}=2,38)$ ve aylık harcama miktarı olarak 1000-1500 TL 
arasına sahip öğrencilerin ( $\bar{X}=2,37)$ sosyal medya konusunda bağımlılık oranlarının çok yakın oldukları söylenebilir.

Tablo 6. Aylık Harcama Miktarlarnna Göre Üniversite Öğrencilerinin Sosyal Medya Bağımlılığına Yönelik Görüşlerinin Tek Yönlü Varyans Analizi (ANOVA) Sonuçları

\begin{tabular}{llllll}
\hline Değişken & $\begin{array}{l}\text { Aylık Harcama } \\
\text { Miktarı }\end{array}$ & $\mathbf{N}$ & $\overline{\mathrm{X}}$ & $\mathbf{S}$ & \\
\hline & $0-500 \mathrm{TL}$ & 73 & 2,30 &, 743 & \\
& $500-1000 \mathrm{TL}$ & 92 & 2,38 &, 713 & \\
& 1000-1500 TL & 21 & 2,37 &, 717 & \\
\hline Harcama & Varyansın & KT & sd & F & p \\
Miktarı & Kaynağı & & & & \\
\hline & Gruplar arası &, 307 & 2 &, 292 &, 747 \\
& Gruplar içi & 96,382 & 183 & & \\
& Toplam & 96,690 & 185 & & \\
\hline
\end{tabular}

\section{Sonuç ve Öneriler}

$\mathrm{Bu}$ araştırmada, sosyal medya bağımlılığına yönelik üniversite öğrencilerinin görüşleri belirlenmiş, öğrencilerin cinsiyet durumları, aylık harcama miktarları, öğrenim gördükleri bölümler ile öğrenci yaşlarının bu görüşlere etkisi incelenmiş ve bazı sonuçlara ulaşılmıştır.

Sosyal medya bağımlılığına yönelik üniversite öğrencilerinin görüşlerinin değerlendirildiği bu çalışmadan elde edilen sonuçlar şu şekildedir:

Araştırmaya katılan üniversite öğrencilerinin verdikleri cevaplarda en yüksek katılımın yalnız kaldıklarında sosyal medyada zaman geçirmek olduğu önermesinin ortaya çıtığ görülmüştür. Sosyal çevreden uzak kaldığında öğrencilerin zaman geçirme aracı olarak sosyal medyayı tercih ettikleri düşünüldüğünde, bu önermeye yüksek katılımın beklenen bir durum olduğunu ifade etmek mümkündür. Bir diğer yüksek katılımın ise sosyal medya kullanımını olup bitenlerden haberdar olma adına tercih ettiğini belirten katılımcı önermesi olmuştur. Üniversitede öğrenim gören öğrenci yaş grubu göz önünde bulundurulduğunda haber alma aracı olarak sosyal medya araçlarını kullanmasının öğrenciler açısından gerekçe olabileceği söylenebilir. Üçüncü bir önermede ise öğrenciler sosyal medya gruplarının paylaşımlarından haberdar olmak için sosyal medyada gezindiklerini 
belirtmektedirler. Bu sayede üniversite öğrencilerinin kendi çevrelerindeki gelişmeler ile ilgili de haber edinme kaynağı olarak sosyal medya araçlarını kullandıkları belirtilebilir. Ayrıca öğrenciler sabah uyandıklarında ilk işlerinin sosyal medyaya girmek olduğu ifadesini de belirtmişlerdir. Bu da öğrencilerin bahsettikleri sosyal medya araçlarını kullanımlarının günün ilk saatlerinden itibaren başladığını gösterebilir. Konu ile ilgili yapılan diğer çalışmalarda benzer sonuçlar görülmüştür (Vural ve Bat, 2010; Alican ve Saban, 2013; Solmaz ve diğ., 2013).

Sosyal medyada iken aç ve susuz kaldığımın farkına bile varmam önerisinin öğrenciler tarafından yeterince benimsenmediğini görmekteyiz. Öğrencilerin sosyal medya kullanıcısı oldukları ancak fiziki anlamda kendilerine zarar verebilecek noktalara kadar kullanımda bulunmadıkları söylenebilir. Yine öğrenciler tarafından düşük oranda katılım önerisi sosyal medyayı sık sık kullanmamdan dolayı ailem ile sorunlar yaşıyorumdur. Üniversite öğrencileri uç noktalarda kullanıcılar olmadıklarını, bu önermeyi de düşük oranda katılımla ifade ettikleri söylenebilir.

Başka bir önermede öğrenciler sosyal medyadaki arkadaşlıkları gerçek yaşamdaki arkadaşlıklara tercih etmediklerini belirtmişlerdir. Öğrencilerin sosyal çevre edinmedeki tercihlerinin halen farklılaşmadığını, yani arkadaş edinmede sosyal medya araçları yerine gerçek çevre ortamlarından yararlandıkları söylenebilir.

Araştırmanın sonucunda, kız öğrencilerin ve erkek öğrencilerin sosyal medya bağımlılığı konusuna yönelik görüşleri incelenmiştir. Bu verilerde öğrencilerin sosyal medya bağımlılı̆̆ı konusuna yönelik görüşlerinde cinsiyet faktörünün önemli olmadığı söylenebilir.

Üniversite öğrencilerinin sosyal medya bağımlılığına yönelik görüşleri öğrencilerin yaş aralıklarına göre anlamlı farklılık göstermemiştir. 18-21 yaş, 21-24 yaş ve 24 yaş ve üzeri öğrencileri görüşlerinin oldukça yakın olduğu görülmektedir. Edinilen bulgulardan yola çıkarak araştırmaya katılan üniversite öğrencilerinin yaş farklarının, sosyal medya kullanımı konusunda, üniversite düzeyi esas alındığında önemli bir faktör olmadığı söylenebilir.

Araştırmaya katılan üniversite öğrencilerinin sosyal medya bağımlılığına yönelik görüşleri öğrenim gördükleri bölüm değişkeni 
açısından incelendiğinde, anlamlı farklılık göstermemiştir. İktisat bölümünde okuyan öğrenciler ile Uluslararası Ticaret ve Lojistik bölümünde okuyan öğrencilerin toplam puanlarının aritmetik ortalamasına bakıldığında oldukça yakın görünmektedir. Yönetim Bilişim Sistemlerinde okuyan öğrencilerin ise toplam puanlarının aritmetik ortalaması diğer iki bölüme göre biraz daha yüksek olduğu tespit edilmiştir. Bu bulgunun, bilişim alanında öğrenim gören öğrencilerin biraz daha fazla sosyal medya ile ilgilendiklerini gösterdiği söylenebilir.

Sosyal medya bağımlılığına yönelik üniversite öğrencilerinin görüşleri incelendiğinde, öğrencilerin aylık ortalama harcadıkları miktar ile sosyal medya bağımlılıkları arasında anlamlı bir farklılık bulunamamiştır.

Öğrencilerin belirttikleri aylık harcama miktarları ile sosyal medya bağımlılığı konusunda bulguların bu şekilde neticelenmesi, öğrencilerin sosyal medya kullanımında ekonomik bir farklılığın kullanımlarını etkilemediğini gösterdiği ifade edilebilir.

Sonuç olarak bu çalışmada üniversite öğrencilerinin sosyal medya bağımlılı̆̆ına yönelik görüşleri incelenmiştir. Öğrencilerin sosyal medya bağımlılı̆̆ına yönelik görüşleri cinsiyet, yaş, bölüm ve aylık harcama miktarları göz önünde bulundurulduğunda anlamlı farklılıklar göstermedikleri belirlenmiştir. Üniversite öğrencilerinin sosyal medya bağımlılı̆̆1 konusunda görüşleri; sosyal medyayı aktif olarak kullandıkları ancak kendilerini bağımlılık seviyesinde görmedikleri şeklinde yorumlanabilir.

$\mathrm{Bu}$ araştırmada örneklem olarak Osmaniye Korkut Ata Üniversitesi öğrencilerinden seçilmiştir. Ülkemizdeki diğer üniversite öğrencilerinin görüşleri incelenebilir ve elde edilen bulgular ile karşılaştırılabilir. Sosyal medya bağımlılığı konusu bu çalışmada bazı değişkenler açısından incelenmiştir. Araştırmada yer alan değişkenler dışında, farklı değişkenler ile sosyal medya bağımlılığı konusunun incelenmesi önerilebilir.

Sosyal medya bağımlılı̆̆ı konusu son zamanlarda bazı kurumlar tarafından üzerinde durulur hale gelmiştir. Örneğin kamuya hizmet veren dernekler ile birlikte sosyal medyanın etkin ve bilinçli kullanılması anlamında eğitimler verilmesi önerilebilir. 


\title{
EXTENDED ABSTRACT
}

\section{Social Media Addiction: Study on University Students}

\author{
Fatih Çağatay Baz \\ Osmaniye Korkutata University
}

Social media has become addictive for the users. Face-to-face interviews have been replaced by virtual environments. It is also observed in the studies that social media addiction causes free time, and this leads to academic failure.

The aim of this study is to determine the views of university students on social media addictions. In addition, it was aimed to determine whether the variables such as age, gender, amount of money spent monthly, and the departments they read differed in their views on the subject.

The problem statement of this research "What are the views of the students studying at Osmaniye Korkut Ata University on social media addiction?"

When the literature is examined, we have not seen any research which examined the views of university students on social media addiction in Osmaniye province. In this sense, it is thought that the study is important.

The study population is comprised of undergraduate students from Osmaniye Korkut Ata University in the spring semester of 2017-2018 academic year. The sample of the study consists of 186 students 3 departments (Economics, International Trade and Logistics, Management Information Systems) in the Faculty of Economics and Administrative Sciences. To determine the sample, non-selective sampling methods, purposive sampling method was preferred.

The questionnaire was applied to collect data. The questionnaire consists of two parts. In the first section, there are items related to personal variables (gender, age, department, monthly expenditure amount). The 
measurement tool used in the second part of the questionnaire was developed to determine social media addiction levels of middle school, high school and university students.

The data obtained from the survey results were analyzed by SPSS 25.0 program. Descriptive statistics, $t$-test for independent samples and oneway analysis of variance were used to analyze the data. In this study, the frequency percentage distributions of the students who participated in the research with descriptive statistics method on social media dependency were calculated.

In this research, the opinions of university students about social media addiction were determined, the effects of gender, monthly spending amounts of the students, the departments they studied and the student ages on these views were examined and some conclusions were reached.

It is seen that the highest participation in university students' answers is seen in the suggestion that I want to spend time in social media alone. Considering that students prefer social media as a means of time when they stay away from the social environment, it is possible to say that high participation in this proposal is expected. The second highest participation is seen in the opinion that we love to use social media to be aware of what is going on. Considering the age group of the university students, it can be said that using social media tools as a means of getting news. In a third proposition, the students state that they are wandering through social media to be aware of the social media groups' sharing. In this way, it can be stated that university students use social media tools as a source of news about the developments in their environment. In addition, when I wake up in the morning, my first job is to enter social media. This may indicate that students' use of the social media tools started from the first hours of the day.

The views of university students on social media dependency did not differ significantly according to age ranges of students. It is seen that the opinions of the students between the ages of 18-21, 21-24 and 24 years are quite close. Based on the findings, it can be said that the age differences of university students who participated in the research were not an important factor in terms of using social media based on university level.

The opinions of university students attending the research on social media dependency did not show a significant difference when they were 
examined in terms of the department variable they studied. The number of students studying in the Department of Economics and International Trade and Logistics seems to be quite close to the arithmetic mean of the total scores of the students. The arithmetic average of the total scores of the students studying in Management Information Systems is found to be slightly higher than the other two sections. It can be said that this finding shows that students studying in the field of informatics are more interested in social media.

When the opinions of university students about social media addiction were examined, there was no significant difference between the average monthly spending of students and social media dependencies. It can be stated that the results of the students' monthly spending amounts and social media addiction results in this way and that the students do not affect the use of social media in an economic difference. The views of university students on social media addiction; social media, but they do not see themselves at the level of dependence.

\section{Kaynakça/References}

Alican, C., ve Saban, A. (2013). Ortaokul ve lisede öğrenim gören öğrencilerin sosyal medya kullanımına ilişkin tutumları: Ürgüp örneği. Sosyal Bilimler Enstitüsü Dergisi, 35 (2). 1-14.

Al-Menayes, J.J. (2015). Dimensions of social media addiction among university students in Kuwait. Psychology and Behavioral Sciences. 4(1). 23-28.

Büyüköztürk, Ş. (2012). Örnekleme yöntemleri. Erişim tarihi: 16.09.2018, http://w3.balikesir.edu.tr/ msackes/wp/wpcontent/uploads/2012/03/BAY-Final-Konulari.pdf

Cabral, J. (2011). Is generation y addicted to social media. The Elon Journal of Undergraduate Research in Communications. 2(1). 5-14.

Çakmak, V. (2014). İletişim kaygısının sosyal medya kullanımı üzerine olan etkisi: üniversite öğrencileri üzerine örnek olay incelemesi. Doktora Tezi. Selçuk Üniversitesi, Konya. 
Demir, Ü. (2016). Sosyal medya kullanımı ve aile iletişimi: Çanakkale'de lise öğrencileri üzerine bir araştırma, Selçuk İletişim, 9 (2), 27-50. doi: 10.18094/si.99029

Hawi, N. S. ve Samaha, M. (2017). The relations among social media addiction, self-esteem, and life satisfaction in university students. Social Science Computer Review, 35(5). 576-586.

Işık, U., ve Topbaş, H. (2015). Facebook ve bağımlılık: medya bağımlılığ araştırması. The Journal of Academic Social Science Studies, 38, 319336.

Kara, T. (2012). Sosyal medya üzerinde yeni nesil pazarlama ve Türkiye bilgi \& iletişim hizmetleri endüstrisinde sosyal ağların kullanımına yönelik bir araştırma. Global Media Journal: Turkish Edition. 2(4), 102-117.

Karasar, N. (2009). Bilimsel araştırma yöntemi (19. Baskı). Ankara: Nobel Yayın Dağıtım

Kırık, A.M., Arslan, A., Çetinkaya, A. ve Gül, M. (2015). A quantitative research on the level of social media addiction among young people in Turkey. International Journal of Science Culture and Sport (IntJSCS), 3(3). 108-122.

Kuss, D.J. ve Griffiths, M.D. (2011). Online social networking and addiction - a review of the psychological literature. International Journal of Environmental Research and Public Health, 8, 3528-3552. doi:10.3390/ijerph8093528

Küçükali, A. (2016). Üniversite öğrencilerinin sosyal medya kullanımı: Atatürk Üniversitesi örneği. Bartın Üniversitesi İ.I.B.F. Dergisi, 7 (13), 531-546.

Nakaya, A.C. (2015). Internet and social media addiction. The United States: Reference Point Press. ISBN-13: 978-1-60152-761-5.

Öngen, O. (2017). Sosyal medya kullanıcılarının gerçeklik yanılgısı. Yeni Medya Elektronik Dergi-eJNM, 1 (1), 1-14.

Sağbaş, E. A., Ballı, S., ve Şen, F. (2016). Sosyal medya ve gençler üzerindeki etkileri. Uluslararası Gençlik Araştırmaları Kongresi., Muğla Sıtkı Koçman Üniversitesi, 153-163.

Şahin, C. (2018). Social media addiction scale - student form: The reliability and validity study. The Turkish Online Journal of Educational Technology,17(1), 169-182. 
Solmaz, B., Tekin, G., Herzem, Z., ve Demir, M. (2013). İnternet ve sosyal medya kullanımı üzerine bir uygulama. Selçuk İletişim, 7(4). 2332.

Vural, Z. B. A., ve Bat, M. (2010). Yeni bir iletişim ortamı olarak sosyal medya: Ege Üniversitesi iletişim fakültesine yönelik bir araştırma. Journal of Yaşar University, 20(5), 3348-3382.

\section{Kaynakça Bilgisi / Citation Information}

Baz, F. Ç. (2018). Sosyal medya bağımlılığı: Üniversite öğrencileri üzerine çalışma. OPUS-Uluslararası Toplum Araştırmaları Dergisi, 9(16), 276-295. DOI: 10.26466/opus.470118 